\title{
COMPARISON OF DIRECT AND INDIRECT METHODS OF TENSILE PROPERTIES DETERMINATION FOR POST-EXPOSED POWER PLANT STEELS
}

\author{
DEDOV, A[ndrei] \& KLEVTSOV, I[van]
}

\begin{abstract}
Long-term exposure at elevated temperatures results in a degradation of the short-term tensile properties of metal that can cause the deterioration in reliability of power equipment. Therefore, in order to avoid unscheduled outages and to guarantee fail-safe operation of equipment periodic control of the tensile properties of metal is highly significant. The comparison of tensile properties values, calculated as a function of metal hardness according to known relations and obtained from the direct tensile testing of some power plant steels is presented in this paper. On the basis of wide disagreement of calculated and measured data was drawn a conclusion about the significance of direct testing of tensile properties.
\end{abstract}

Keywords: tensile properties, tensile testing, hardness, power plant steels, high temperature

\section{INTRODUCTION}

One of the most important missions in heat-andpower engineering is increasing the durability and operating reliability of new components of power equipment as well as components that had exceeded the nominal design life. Boilers and turbines of Narva power plants in Estonia were designed for 100 thousands hours of operation, but the basic components (except for unit 8 of Eesti power plant and unit 11 of Balti power plant) have been already operated $250 \ldots 280$ thousands hours. Nowadays such components of power equipment require continuous inspection and replacement (if it is needed). In this case in respect to safe and reliable operation of equipment it is highly significant to be able to determine life consumption and estimate the remaining life of the component or the life till the next mandatory inspection as accurate as possible. It allows optimize the amount and cost of inspection and avoid unscheduled outages and unreasonable replacement of components, which is rather expensive procedure.

\section{TENSILE PROPERTIES DEGRADATION}

According to [1] the short-term mechanical properties of metal could not be used as a criterion for determination of current state of damage of power equipment components, operated in creep conditions. The main process that allows determining life consumption of component is accumulation of metal structure damages, caused by creep and fatigue of metal under influence of high temperatures and stresses and their fluctuations. On the other hand, changes in microstructure of metal, which occur in metal during long-term exposure in conditions of creep, can cause a degradation of short-term tensile properties [2-9]. The influence of long-term operation on tensile properties of perlitic steel $12 \mathrm{Ch} 1 \mathrm{MF}$ (analogue steels are $2 \frac{1}{4} \mathrm{Cr}-1 \mathrm{Mo}$, 10CrMo9-10), which is commonly used in steam piping manufacturing, was investigated in [4]. It is shown, that a long-term exposure of steel $12 \mathrm{Ch} 1 \mathrm{MF}$ at elevated temperatures leads to decreasing of tensile strength $\left(R_{m}\right)$. Tensile strength, measured at operating temperature $\left(R_{m / t}\right)$, decreases more markedly. Moreover, author proposes to use the ratio of tensile strength measured at operating temperature to tensile strength measured at room temperature $\left(R_{m / t} / R_{m}\right)$ as one of reliability parameters. According to [4] the minimum allowable value of the ratio for steel $12 \mathrm{Ch} 1 \mathrm{MF}$ is 0.48 at 560 $570^{\circ} \mathrm{C}$ and 0.55 at $540-545^{\circ} \mathrm{C}$.

The influence of long-term operation at high temperature on yield strength $\left(R_{p 0.2}\right)$ of perlitic steels $12 \mathrm{Ch} 1 \mathrm{MF}$ and $2 \frac{1}{4} \mathrm{Cr}-1 \mathrm{Mo}$, measured at room temperature is presented in Fig. $1[5,6,7]$. The steel $2 \frac{1}{4} \mathrm{Cr}-1 \mathrm{Mo}$, which is also used for manufacturing of steam piping and headers, was investigated in Babcock \& Wilcox [7]. The results of investigation have shown an evident tendency of the subsequent yield strength steady decrease during service time at high temperatures (Fig. 1). It is seen, that after 200 thousands hours of operation at $540^{\circ} \mathrm{C}$ yield strength of steel $12 \mathrm{Ch} 1 \mathrm{MF}$ decreases approximately by $7 \%$, and for steel $2 \frac{1}{4} \mathrm{Cr}-1 \mathrm{Mo}$ the decrease of yield strength is $24 \%$. Investigation of steam turbine rotor steel Cr-Mo-V [8] has shown the decrease of tensile strength and yield strength after 200 thousands hours of operation at $530^{\circ} \mathrm{C}$ from 939 to 855

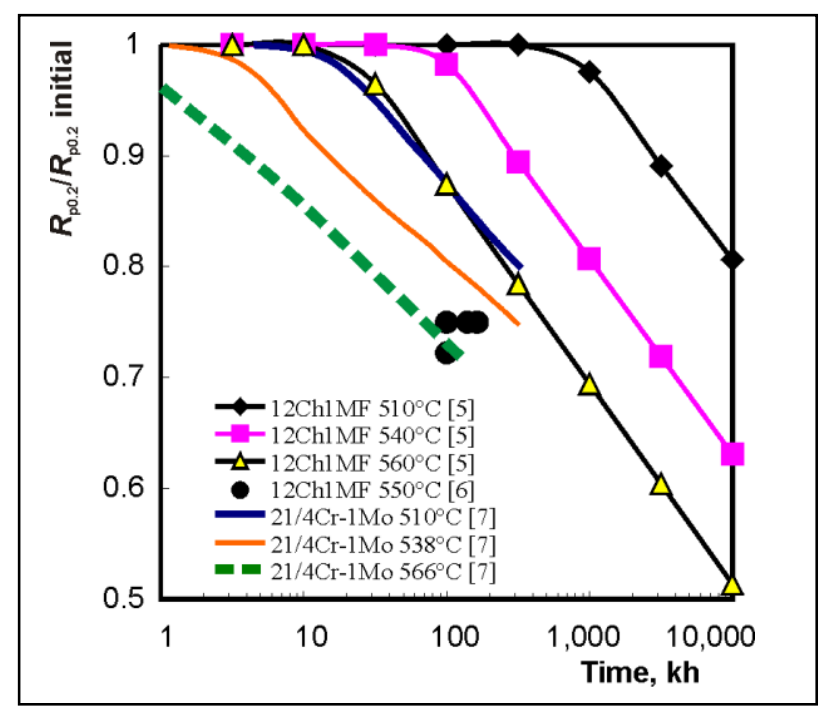

Fig. 1. Effect of service time and temperature on the yield strength of steels $12 \mathrm{Ch} 1 \mathrm{MF}[5,6]$ and $2 \frac{1}{4} \mathrm{Cr}-1 \mathrm{Mo}[7]$ 


\begin{tabular}{|c|c|c|c|c|}
\hline \multirow{2}{*}{ Steel } & \multicolumn{2}{|c|}{ SMiS “Donbassenergo" } & \multicolumn{2}{c|}{ Ural VTI } \\
\cline { 2 - 5 } & $R_{\mathrm{p} 0.2}, \mathrm{MPa}$ & $R_{\mathrm{m}}, \mathrm{MPa}$ & $R_{\mathrm{p} 0.2}, \mathrm{MPa}$ & $R_{\mathrm{m}}, \mathrm{MPa}$ \\
\hline \multirow{4}{*}{$12 \mathrm{Ch} 1 \mathrm{MF}$} & & $\mathrm{HB}=100-175$ & & \\
& $\mathrm{HB}=100-175$ & $3.5 \mathrm{HB}$ & \multirow{2}{*}{$2.35 \mathrm{HB}+18$} & $3.35 \mathrm{HB}+18$ \\
& $5.45 \mathrm{HB}-480$ & $\mathrm{HB} \geq 175$ & & \\
& & $3.6 \mathrm{HB}$ & & \\
\hline
\end{tabular}

Tab. 1. Relationship between tensile properties and Brinell hardness for perlitic steel 12Ch1MF [11, 12].

$\mathrm{N} / \mathrm{mm}^{2}(9 \%)$ and from 786 to $686 \mathrm{~N} / \mathrm{mm}^{2}(13 \%)$ respectively. According to investigation of carbon steel St. 20 [9], operation at $450{ }^{\circ} \mathrm{C}$ leads to decrease of tensile strength by $13 \%$ and yield strength by $20 \%$ after 79 thousands hours. Consequently, long-term exposure at elevated temperatures in the conditions of creep results in a degradation of the short-term tensile properties of metal for all investigated power plant steels. Moreover the decrease of short-term tensile properties for some steels is specified in standards [10]. So, the allowable decrease of short-term tensile properties (tensile strength and yield strength) after 100 thousands hours of exposure for metal of steam pipelines (straight sections and bends), which are operated in conditions of creep, is not more than $30 \mathrm{~N} / \mathrm{mm}^{2}$ in comparison with requirements for the new material. The ratio of yield strength to tensile strength $\left(R_{p 0.2} / R_{m}\right)$ measured at room temperature should also satisfy certain requirements (e.g. for metal of boiler drum the ratio should not exceed 0.7 for carbon steels and 0.8 for alloyed steels [10]). Thus, in order to determine the life consumption and current state of damage of power plant components in addition to analysing of metal structure it is highly significant to measure periodically tensile properties of the metal.

\section{COMPARISON OF DIRECT AND INDIRECT METHODS OF TENSILE PROPERTIES DETERMINATION.}

Traditional destructive methods of mechanical properties evaluation by means of tension tests of standard specimens require removing metal from the component in great quantities and hence the replacement of the component. Therefore in order to reduce the cost of the metal examination and to determine the material properties of the in-service components without necessity of the replacement indirect techniques of the mechanical properties evaluation have been developed. These techniques are based on the relationship between tensile properties and hardness, which can be easly measured in situ without metal removing by using of portable hardness testers. In this case prior to hardness testing it is necessary just to polish the surface of the component. Particularly, the methods of SMiS "Donbassenergo" and Ural VTI [11, 12] are used for determining the tensile strength and yield strength of some steels, which are used for manufacturing of the basic components of power plants in Estonia. The equations of Brinell hardness number (HB) conversion into tensile properties of perlitic steel 12Ch1MF are presented in Tab. 1.

In order to analyse the validity of using abovementioned methods, the results of metal testing during many years in the laboratory, are taken into consideration. The values of tensile strength and yield strength obtained from the tension tests of standard cylindrical specimens fabricated from unexposed steel $12 \mathrm{Ch} 1 \mathrm{MF}$ and Brinell hardness measured by means of bench-top testers have been selected. The comparison of tensile properties measured by means of tensile testing at temperature of $20^{\circ} \mathrm{C}$ and calculated depending on Brinell hardness values is presented in Fig. 2. It is seen, that the results of the real direct tensile tests and calculated data have shown quite a good agreement. However the ratio of yield strength to tensile strength could not be practically predicted on the basis of hardness values with acceptable accuracy (Fig. 3). Moreover according to equations of Ural VTI the ratio $R_{p 0.2} / R_{m}$ is practically the constant value that is not valid.

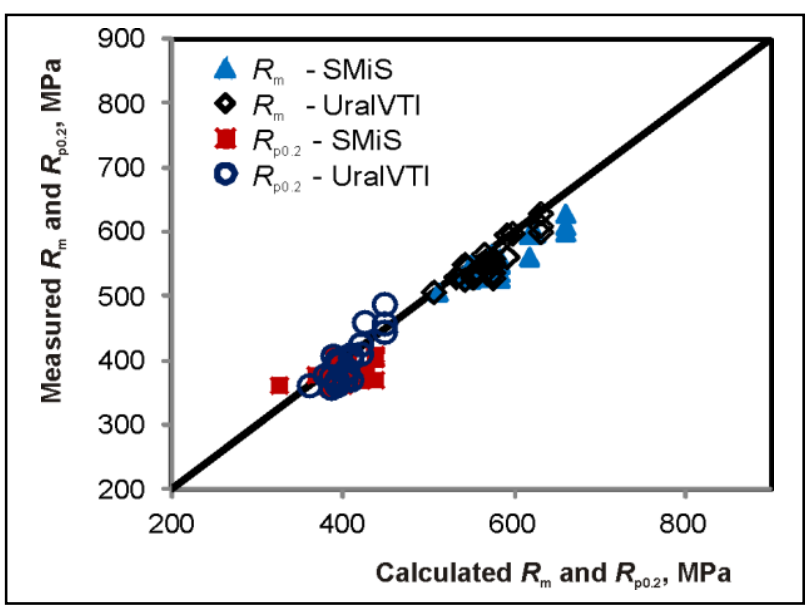

Fig. 2.Tensile strength and yield strength of steel 12Ch1MF measured by tensile testing at temperature of $20^{\circ} \mathrm{C}$ and calculated depending on Brinell hardness values according to the correlations of SMiS "Donbassenergo" and Ural VTI.

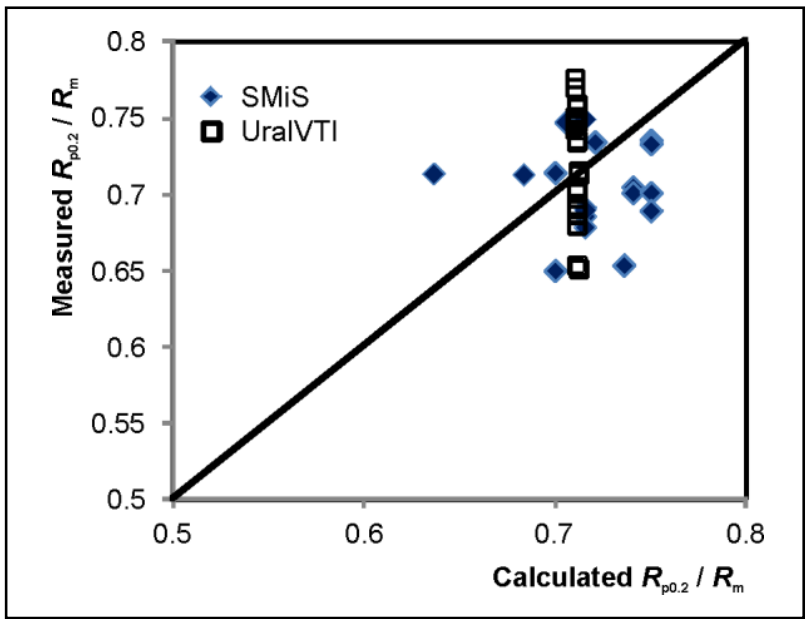

Fig. 3.The ratio of yield strength to tensile strength of steel $12 \mathrm{Ch} 1 \mathrm{MF}$ measured by tensile testing at temperature of $20^{\circ} \mathrm{C}$ and calculated depending on Brinell hardness values according to the correlations of SMiS "Donbassenergo" and Ural VTI.

The measurements of post-exposed at elevated temperature material have shown that it is impossible to 
find functional relation between yield to tensile ratio and service time (Fig. 4) or between yield strength and tensile strength at room temperature (Fig. 5). Thus, it is valid to consider, that it is impossible to estimate the yield strength depending on measured tensile strength with acceptable accuracy. At the same time the yield strength is a very essential parameter for the operational integrity assessment of some components (e.g. turbine casing). The measurements of post-exposed material, conducted at operating temperature of $540{ }^{\circ} \mathrm{C}$ have shown significantly higher scatter of the data (Fig. 6).

Another comparative analysis of real tensile properties and converted from hardness values has been carried out. Tensile properties have been determined by

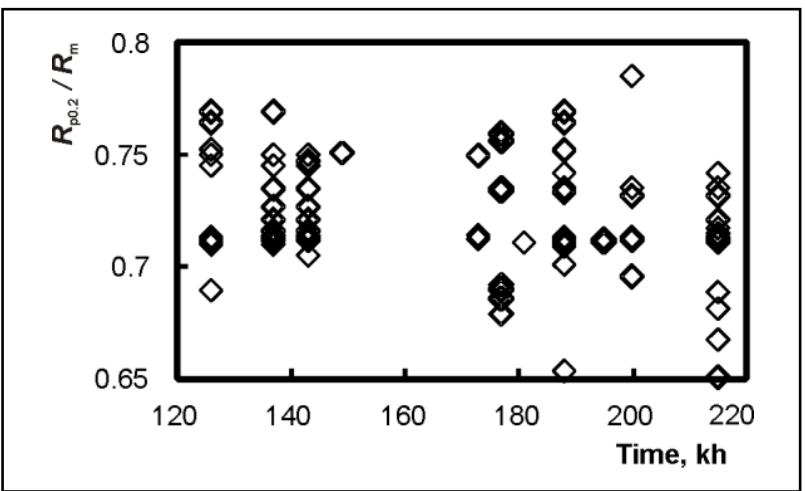

Fig. 4. Relationship between the ratio of yield strength to tensile strength $R_{p 0.2} / R_{m}$ of post-exposed steel $12 \mathrm{Ch} 1 \mathrm{MF}$ at temperature of $20^{\circ} \mathrm{C}$ and service time

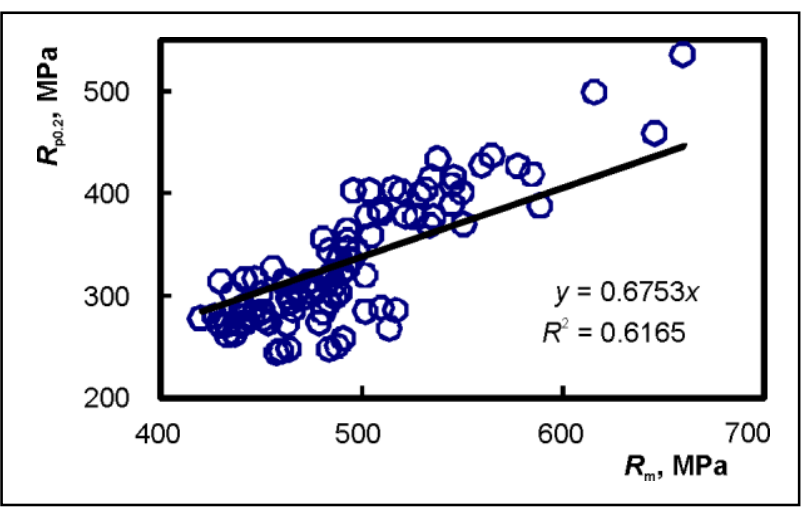

Fig. 5. Relationship between the yield strength $R_{\mathrm{p} 0.2}$ and tensile strength $R_{\mathrm{m}}$ of post-exposed steel $12 \mathrm{Ch} 1 \mathrm{MF}$ at temperature of $20^{\circ} \mathrm{C}$

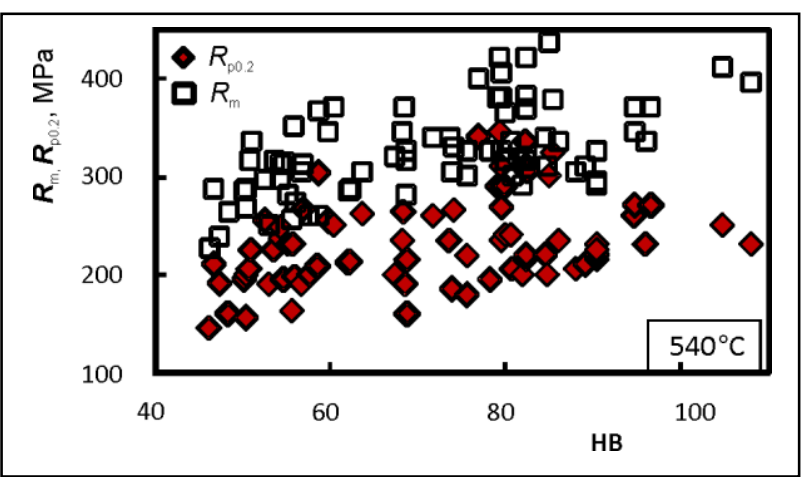

Fig. 6. Relationship between the yield strength $R_{\mathrm{p} 0.2}$, tensile strength $R_{\mathrm{m}}$ and hardness $\mathrm{HB}$ of post-exposed steel $12 \mathrm{Ch} 1 \mathrm{MF}$ at $540^{\circ} \mathrm{C}$

tensile testing of the miniature flat specimens (Fig. 7), which have been fabricated from the samples extracted from the in-service components [2]. The metal hardness has been measured by portable testers (type 54-359 M) on the surface of the dimple, remained after sample extraction (Fig. 8). It should be mentioned, that the hardness has been measured not from the surface layer but at a depth of about $2-3 \mathrm{~mm}$ from the surface of the component, that represents the properties of bulk metal. A detailed review of the sampling devices, experience in metal extraction of miniature samples is presented in [13, 14]. The results of tensile testing of miniature specimens, conducted at room temperature, were compared with calculated values depending on metal hardness. In Fig. 9 it is clearly seen, that the values, predicted by correlations, are significantly higher, than the values of mechanical properties, obtained from direct tensile testing. The ratio of yield strength to tensile strength also practically could not be predicted (Fig. 10).

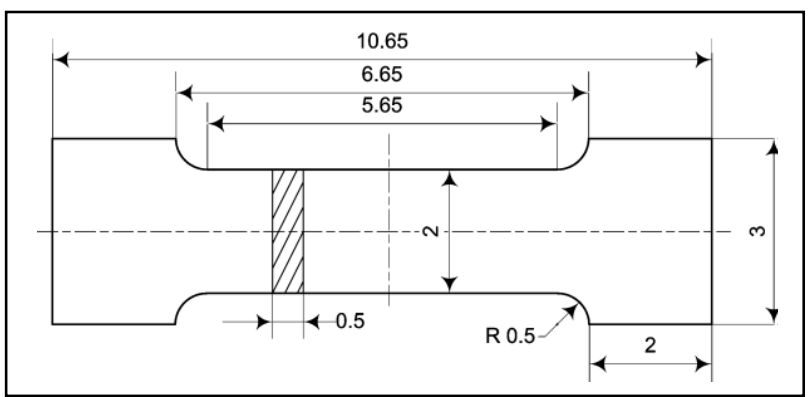

Fig. 7. Miniature specimen for tensile testing (all dimensions are in $\mathrm{mm})$

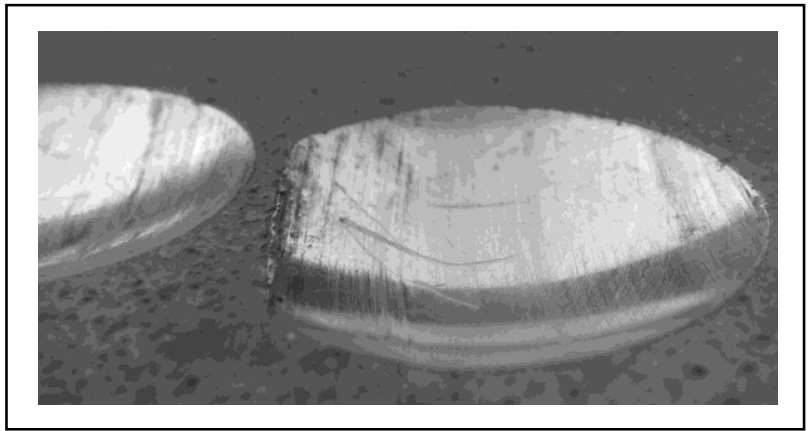

Fig. 8. Dimple remained after metal sampling

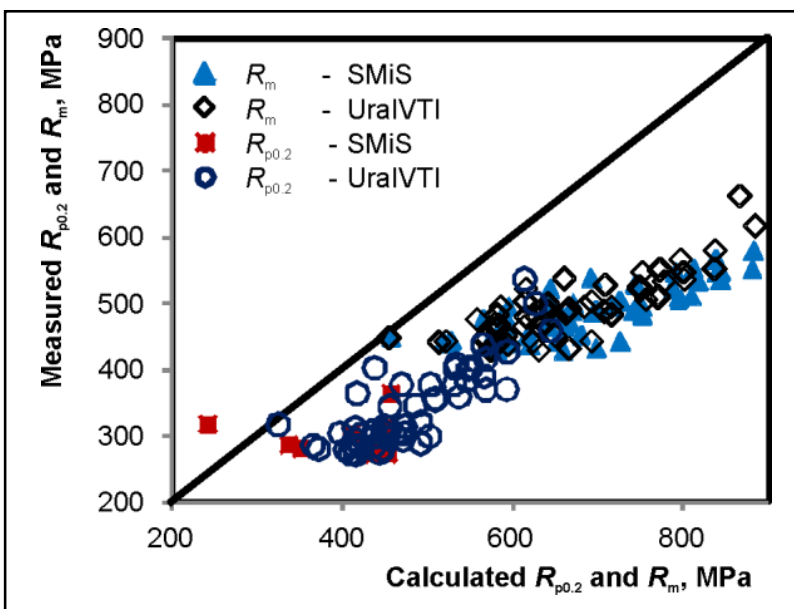

Fig. 9. Tensile strength $R_{\mathrm{m}}$ and yield strength $R_{\mathrm{p} 0.2}$ of steel $12 \mathrm{Ch} 1 \mathrm{MF}$ measured at room temperature and calculated depending on Brinell hardness measured on the surface of the dimple 


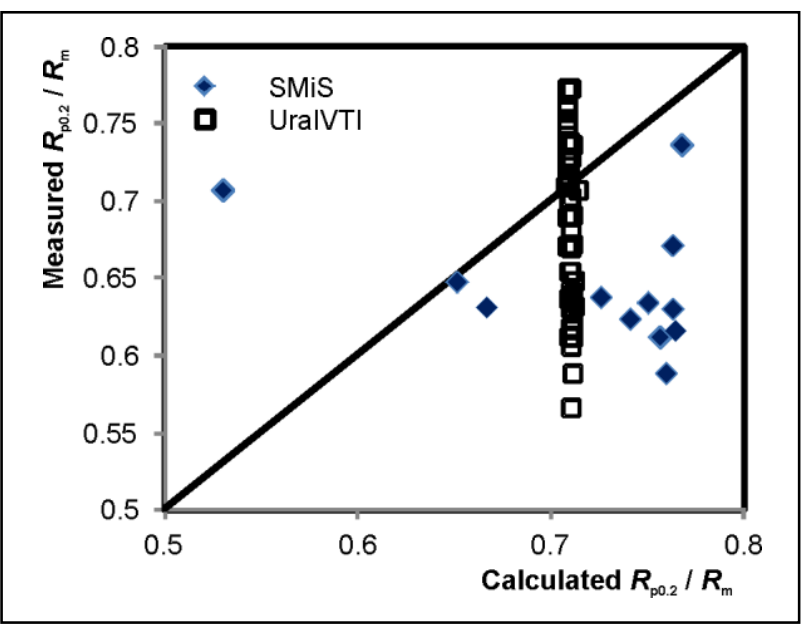

Fig. 10. Yield strength and tensile strength ratio $R_{p 0.2} / R_{m}$ of steel $12 \mathrm{Ch} 1 \mathrm{MF}$ measured at room temperature and calculated depending on Brinell hardness measured on the surface of the dimple

It should be briefly mentioned, that automated ball indentation (ABI) technique [15] could be also applied to evaluate the tensile properties of metal. ABI is nondestructive technique, which is based on ball indentation and the uniqueness of which is the fact that this technique does not require post measurement of the diameter of indentation. According to [15] ABI allows determining several tensile properties (e.g. yield strength, tensile strength). However, plasticity of the metal (percent elongation and reduction of area, which are very important parameters in estimation of durability of such components as boiler drums, piping) could not be measured by this technique, neither by conversion of hardness values.

In addition, it should be emphasised that in contrast to direct tensile tests neither ABI technique, nor the converted hardness values do not provide the information whether obtained tensile properties are in the longitudinal or transverse direction. It should be also pointed out, that both of the methods provide data about properties of the surface layer of the component, which are unrepresentative of bulk metal properties. So, in view of surface effects such as oxidation or carbon depletion, either during manufacturing or in service, mechanical properties of the surface layer are significantly different from properties of the bulk metal.

\section{CONCLUSION}

The comparison of the tensile properties of postexposed material, obtained from the direct tensile testing and calculated as a function of measured hardness according to indirect techniques, has shown a vital importance of direct testing in order to determine tensile strength, yield strength and ductility properties. The mentioned indirect techniques are not sufficiently reliable for the metal which has been subjected to long-term operation at high temperature and could not substitute the direct tensile tests. Thus the tensile properties of the actual material can be obtained only by means of direct tensile testing. The complete material behaviour could be adequately and reliably depicted only by the entire stressstrain curve, which could not be provided by indirect techniques. Thus, direct testing of tensile properties is the only reliable source of data.

\section{ACKNOWLEDGEMENTS}

Present research was supported by Estoinan Science Foundation grant No ETF8633 (Assessment of metall condition of power plant equipment).

\section{REFERENCES}

[1] Kumanin V., Kovalyova L., Aleksejev S. (1988). Durability of Metal in the Conditions of Creep. Metallurgia, ISBN: 5-22900167-4, Moscow, (in Russian)

[2] Klevtsov I., Dedov A. (2009). Condition assessment of power plant components operating under creep by testing of miniature specimens. Proceedings of $2^{\text {nd }}$ ECCC Creep Conference Creep \& Fracture in High Temperature Components, 21-23 April 2009, Zurich, Switzerland, ISBN: 978-1-60595-005-1, Shibli I., Holdsworth S. (Ed.), pp. 1126-1137, DEStech Publications, Lancaster USA

[3] Bugay N., Berezina T., Trunin I. (1994). Reliability and durability of Power Equipment Metal. Energoatomizdat, ISBN: 5-283-2217, Moscow, (in Russian)

[4] Antikain P. (1990). Metals and Stress Calculation of Boilers and Piping. Energia, ISBN: 5-283-00065-6, Energoatomizdat, Moscow, (in Russian)

[5] Berezina T. (2004). Key to steels and alloys in Thermal Engineering. Handbook, Chelyabinsk, (in Russian)

[6] Ray A.K., Tiwari Y.N., Sinha R.K., Chaudhuri S., Singh R. (2000). Residual life prediction of service exposed main steam pipe of boilers in a thermal power plant. Engineering Failure Analysis, No. 7, pp. 359-376, ISSN: 1350-6307

[7] Nakoneczny Greg J., Schultz Carl C. (1995). Life assessment of High Temperature Headers. Proceedings of American Power Conference, 1995, April 18-29, Chicago, USA. ISSN: 0097-2126

[8] Cheruvu N.S. (1989). Degradation of mechanical properties of Cr$\mathrm{Mo}-\mathrm{V}$ and $2.25 \mathrm{Cr}-1 \mathrm{Mo}$ steel components after long-term service at elevated temperatures. Metallurgical Transactions, Vol. 20A, No. 1, Jan, 1989, pp.-87-97, ISSN: 0360-2133

[9] Smirnova A., Balashov Y., Tikhonova T., Ivanova L. (1993). Degradation of Structure and Mechanical Properties of Steel 20 During Long-Term Operation at Temperatures Higher than $450^{\circ} \mathrm{C}$. Teploenergetika, 1993 nr. 11, pp. 11-13, ISSN: 0040-3636 (in Russian)

[10] CTO 17230282.27.100.005-2008. Basic components of power plant boilers, turbines and pipes. Metal inspection. Standards and requirements (in Russian)

[11] Instruction of mechanical properties and impact toughness determining of power plant equipment metal by non-destructive testing. SMiS "Donbassenergo", 1978 (in Russian)

[12] Methodical instructions of hardness and mechanical properties determining of low alloyed steels of power equipment without specimens testing, Ural VTI, 1978 (in Russian)

[13] Dedov, A., Klevtsov, I., Lausmaa, T. and Neshumayev, D. (2007). Method of small samples for assessment of properties of power plant components: sampling devices and stress concentration in dimples. Proceedings of Conference BALTICA VII on Life Management and Maintenance for Power Plants, 12-14 June 2007, Helsinki - Stockholm, ISSN: 0357-9387, ISBN: 978-951386317-3, Veivo J., Auerkari P. (Ed.), Vol. 2, pp. 180-192, VTT Technical research centre of Finland

[14] Data acceptability criteria and data generation: recommendations for creep testing of post exposed (ex-service) materials. (2003). ECCC recommendations, Vol. 3 (III). Available from: http://www.ommi.co.uk/etd/eccc/advancedcreep/V3PIIIi4x.pdf. Accessed: 2012-04-30

[15] Haggag F., Murty K. (1997). A Novel Stress-Strain Microprobe for Nondestructive Evaluation of Mechanical Properties of Materials. Nondestructive Evaluation and Materials Properties III, The Minerals, Metals \& Materials Society, 1997, pp. 101-106, ISSN: 0361-5235 